\title{
Vampires and nurses are rated differently by younger and older adults-Age-comparative norms of imageability and emotionality for about 2500 German nouns
}

\author{
Thomas H. Grandy ${ }^{1,2}$ • Ulman Lindenberger ${ }^{1}$ • Florian Schmiedek ${ }^{1,3}$
}

Published online: 12 February 2020

(C) The Author(s) 2020

\begin{abstract}
Imageability and emotionality ratings for 2592 German nouns (3-10 letters, one to three phonological syllables) were obtained from younger adults (21-31 years) and older adults (70-86 years). Valid ratings were obtained on average from 20 younger and 23 older adults per word for imageability, and from 18 younger and 19 older adults per word for emotionality. The internal consistency (Cronbach's $\alpha$ ) and retest rank-order stability of the ratings were high for both age groups ( $\alpha$ and $r \geq .97$ ). Also, the validity of our ratings was found to be high, as compared to previously published ratings $(r \geq .86)$. The ratings showed substantial rank-order stability across younger and older adults (imageability, $r=.94$; emotionality, $r=.85$ ). At the same time, systematic differences between age groups were found in the mean levels of ratings (imageability, $d=0.38$; emotionality, $d=0.20$ ) and in the extent to which the rating scales were used (imageability, $S D=24$ vs. 19 , scale of 0 to 100 ; emotionality, $S D=26$ vs. 31 , scale of -100 to 100). At the descriptive level, our data hint at systematically different evaluations of semantic categories regarding imageability and emotionality across younger and older adults. Given that imageability and emotionality have been reported, for instance, as important determinants for the recognition and recall of words, our findings highlight the importance of considering age-specific information in age-comparative cognitive (neuroscience) experimental studies using word materials. The age-specific imageability and emotionality ratings for the 2592 German nouns can be found in the electronic supplementary material 1 .
\end{abstract}

Keywords Imageability $\cdot$ Imagery $\cdot$ Emotionality $\cdot$ Valence $\cdot$ Age differences

The present study provides age-comparative ratings for 2592 German nouns for imageability - as the capacity to evoke perceptual or mental images - and emotionality - as the capacity to elicit pleasant or unpleasant and awkward feelings or emotions - from younger (21-31 years old) and older (70-

Electronic supplementary material The online version of this article (https://doi.org/10.3758/s13428-019-01294-2) contains supplementary material, which is available to authorized users.

Thomas H. Grandy

thomas.grandy@charite.de

1 Center for Lifespan Psychology, Max Planck Institute for Human Development, Berlin, Germany

2 Working Group on Cardiovascular Magnetic Resonance, Experimental and Clinical Research Center - a joint cooperation between the Charité Medical Faculty and the Max Delbrück Center for Molecular Medicine and HELIOS Hospital Berlin-Buch, Department of Cardiology and Nephrology, Berlin, Germany

3 DIPF | Leibniz Institute for Research and Information in Education, Frankfurt am Main, Germany
86 years old) adults. The imageability and emotionality of words have been found to be important determinants for their recognition and recall in memory experiments (e.g., Kensinger, Brierley, Medford, Growdon, \& Corkin, 2002; Paivio, Yuille, \& Rogers, 1969; Rubin \& Friendly, 1986). Moreover, age differences between younger and older adults in imageability and emotionality ratings have been reported (e.g., Grühn \& Smith, 2008; Kensinger, Brierley, Medford, Growdon, \& Corkin, 2002), thus implicating these word characteristics as a potential confound in age-comparative memory experiments. Nonetheless, despite the prominent role of memory as a topic in research on cognitive aging and the cognitive neuroscience of aging (e.g., Brod, Werkle-Bergner, \& Shing, 2013; Lindenberger, 2014; Shing, Werkle-Bergner, Brehmer, Müller, Li, \& Lindenberger, 2010), so far age-specific information regarding imageability and emotionality of words has been lacking for a larger body of German nouns (Kanske \& Kotz, 2010; Lahl, Göritz, Pietrowsky, \& Rosenberg, 2009; Schmidtke, Schröder, Jacobs, \& Conrad, 2014; Võ et al., 2009; Võ, Jacobs, \& Conrad, 2006; see also Hager \& Hasselhorn, 1994a). The primary goal of the present study 
was to provide researchers with age-specific information for a large body of German nouns to control for or rule out differences in memory performance that may be attributed to differences in imageability and emotionality of presented words. Word ratings presented here have been implemented in a large-scale cognitive training study (Schmiedek, Lövdén, \& Lindenberger, 2010).

Imageability (or imagery) as a psychological construct was introduced to experimental psychology by Paivio (1965) and has been ever since in the focus of memory research. On the one hand, imageability of words has been found to influence recall and recognition performance (e.g., Cortese, Khanna, \& Hacker, 2010; Cortese, McCarty, \& Schock, 2015; Paivio et al., 1969; Rubin \& Friendly, 1986). On the other hand, imagery instructions - that is, the instruction to encode the presented words (or word pairs) as vivid images - are commonly employed in memory tasks (e.g., Bower, 1970; Paivio, 1971; Richardson, 1998; Shing, Werkle-Bergner, Li, \& Lindenberger, 2008). Imageability ratings for words have been found to differ across different age groups (e.g., Emmerich, 1979; Forisha, 1975; Grühn \& Smith, 2008). Consequently, as imageability plays an important explicit (by instruction) as well as implicit (by moderating performance) role in memory experiments, identification of words that differ considerably in their imageability across age groups is of high relevance.

The emotionality of stimuli has equally been reported to enhance their recall and recognition (Adelman \& Estes, 2013; Hamann, 2001; Hamann, Cahill, \& Squire, 1997; Kensinger et al., 2002; Rubin \& Friendly, 1986). Grühn and Smith (2008) reported reliable differences in emotionality ratings between younger and older adults for a considerable number of adjectives. Moreover, several studies reported an influence of the emotionality of stimuli on age-related differences in memory (Charles, Mather, \& Carstensen, 2003; Grühn, Scheibe, \& Baltes, 2007; Grühn, Smith, \& Baltes, 2005; Kensinger et al., 2002). Notably, findings reported by Kensinger and colleagues suggest that age-related differences in the recall of emotional words may be accounted for by agerelated differences in the ratings of words as emotionally neutral, positive, or negative (see also Grühn \& Smith, 2008). Consequently, the emotionality of words is an important property to control for in age-comparative cognitive (neuroscience) experiments.

The primary goal of the present study was to fill in the gap of age-specific imageability and emotionality norms for a larger body of German nouns as experimental control over known confounding factors is important to unambiguously understand changes in memory processes and the memory system across the lifespan. Nonetheless, the information provided may also be employed beyond memory research in the selection, control, manipulation, or analysis of stimulus characteristics in other experimental cognitive (neuroscience) settings (cf. Balota, Cortese, Sergent-Marshall, Spieler, \& Yap, 2004; Cortese \& Fugett, 2004).

Of note, the instructions for the word-rating procedure closely followed the recommendations in Hager and Hasselhorn (1994a; see also Cortese \& Fugett, 2004; Toglia \& Battig, 1978). Imageability and emotionality ratings for 725 and 556 words, respectively, out of the 2592 words were reported in Hager and Hasselhorn (1994b; see also Baschek, Bredenkamp, Oehrle, \& Wippich, 1977; Offe, Anneken, \& Kessler, 1981; Schwibbe, Räder, Schwitte, Borchardt, \& Geiken-Pophanken, 1981), thus allowing us to assess the validity of the present word ratings in comparison to previously reported German word norms.

\section{Method}

\section{Participants}

The final sample comprised 29 younger $\left(M_{\mathrm{age}}=26.2\right.$ years, $S D=2.3$, range $=21-31$ years; 15 women, 14 men) and 32 older $\left(M_{\text {age }}=75.4\right.$ years, $S D=3.5$, range $=70-86$ years; 17 women, 15 men) adults for imageability ratings, and 26 younger $\left(M_{\mathrm{age}}=26.2\right.$ years, $S D=2.8$, range $=21-31$ years; 13 women, 13 men $)$ and 25 older $\left(M_{\text {age }}=75.0\right.$ years, $S D=3.9$, range $=70-86$ years; 13 women, 12 men) adults for emotionality ratings. The participants were recruited from the participant pool of the Max Planck Institute for Human Development, Berlin, Germany (MPIB). All participants gave written informed consent according to institutional guidelines of the ethics committee of the MPIB and were paid for their participation ( $€ 10$ per hour).

Participants who indicated that more than $1 \%$ of the rated words were unknown were excluded from further analyses (for the imageability ratings, three younger and one older adults were excluded; for the emotionality ratings, two younger and three older adults were excluded; see Fig. 1). For the final sample, the percentage of words rated as unknown amounted to $0.14 \% \pm 0.21 \%$ for the imageability ratings (range $=0.0 \%$ to $0.9 \%$ ), and $0.10 \% \pm 0.16 \%$ (range $=0.0 \%$ to $0.6 \%$ ) for the emotionality ratings, across both age groups.

\section{Word corpus}

In all, 2592 German nouns with two to ten letters and one to three phonological syllables (one noun with four phonological syllables) were rated with respect to imageability and emotionality. The overall word corpus was compiled from existing German word corpora and previous studies conducted at the MPIB (Baayen, Piepenbrock, \& Gulikers, 1995; Hager \& Hasselhorn, 1994b; Shing et al., 2008; Singer, Lindenberger, \& Baltes, 2003). In addition, 261 high-frequency words from the CELEX lexical database (Baayen et al., 1995) were added. 


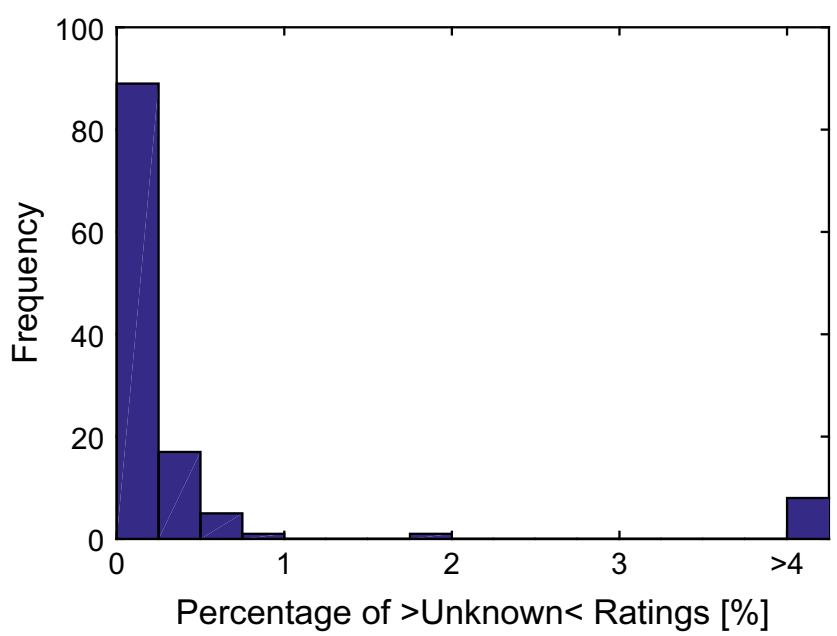

Fig. 1 Frequency of relative occurrences of words rated as "unknown", across age groups and imageability and emotionality ratings.

All but 40 words are contained in the CELEX lexical database.

\section{Procedure}

Participants took part in up to three 2-h sessions for the imageability and emotionality ratings, separately. The data were collected in 2005 . For imageability ratings, the younger adults participated on average in $1.8 \pm 0.9(S D)$ sessions, rating on average $1824 \pm 824$ words, and the older adults took part in $2.3 \pm 0.9$ sessions, rating on average $1887 \pm 790$ words. For emotionality ratings, the younger adults participated on average in $1.7 \pm 0.8$ sessions, rating on average $1857 \pm 770$ words, and the older adults took part in $2.2 \pm 0.8$ sessions rating on average $2014 \pm 737$ words.

Participants were tested in groups of up to 20 in a large room. Word rating was conducted self-paced on personal computers. Participants were instructed with a standardized PowerPoint presentation regarding the general procedure and the criteria by which the nouns had to be rated prior to the word rating (see below). In addition, every participant obtained a printout of the instructions (see the Appendix) and could ask for assistance at any time during the session. To ensure equivalent anchoring of the ratings, a printed-out list of 25 words was provided, and the rating in each session started with these 25 anchor words (see the Appendix). For these 25 words, the ratings of the first session are reported in the word norm table. Moreover, the aggregated ratings of these 25 words for the first session served to estimate the consistency (Cronbach's $\alpha$; Cronbach, 1951), and for the first and second sessions, to estimate the reliability (rank-order stability), of the aggregate ratings.

The 25 anchor words and the remaining 2567 words were presented in random order. To ensure comparable numbers of ratings for every word, the number of ratings obtained per word was monitored online, and the words with fewer ratings were presented with higher probability. The average number of valid imageability ratings per word was $20.1 \pm 1.3$ (SD; range $=14$ to 29 ) in younger adults, and $22.9 \pm 1.0$ (range $=$ 20 to 32 ) in older adults. For the emotionality ratings, the average number of valid ratings per word was $18.4 \pm 1.0$ (range $=9$ to 26$)$ in younger, and $19.1 \pm 0.7$ (range $=8$ to 25 ) in older, adults.

The words to be rated were presented in the middle of the computer screen. A bar together with a pointer was presented below the presented word. The bar was marked at the ends and the midpoint with the respective scale values - that is, 0,50 , and 100 for the imageability ratings, and $-100,0$, and 100 for the emotionality ratings (see Fig. 2). Participants could either click with the cursor of their computer mouse at a location on the scale where they intended to place their rating, or pull the pointer along with their mouse cursor. A field above the scale indicated the specific numeric value that participants had assigned to the presented word. If participants were fine with their rating, they could click on the "continue" button. If a presented word was highly unfamiliar or was unknown to participants, they were instructed to indicate this by clicking with the cursor on the "unknown" button.

For imageability ratings, participants were instructed to rate the nouns regarding their capacity to evoke perceptual or mental images (cf. Paivio, Yuille, \& Madigan, 1968; Paivio et al., 1969) on a scale from 0 to 100 . Specifically, they were instructed to assign high numeric values if the presented word elicited perceptual or mental images promptly and easily, and to assign low numeric values if the presented word elicited perceptual images only slowly and with difficulty; if words generated perceptual or mental images neither easily nor with difficulty, participants were instructed to assign values around the middle of the scale. Furthermore, they were explicitly advised only to rate the presented word, and not to include associated perceptual or mental images that were evoked by the presented word (cf. Cortese \& Fugett, 2004).

For emotionality ratings, participants were instructed to rate the nouns regarding their capacity to elicit pleasant or unpleasant and awkward feelings or emotions (cf. Rubin \& Friendly,

\section{Word}

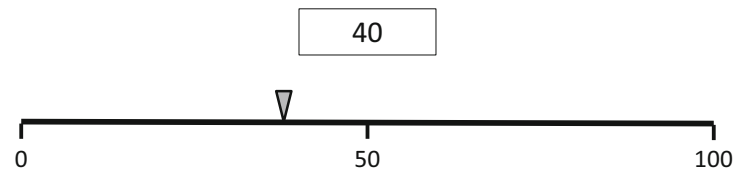

'Unknown' Continue

Fig. 2 Layout of the presentation of a word and the rating scale on the computer screen. 
Table 1 Cronbach's $\alpha$ for the ratings of the first 25 words in the first session, rated by all participants

\begin{tabular}{llllll}
\hline Age Group & \multicolumn{2}{l}{ Imageability } & & & \multicolumn{2}{l}{ Emotionality } \\
\cline { 2 - 3 } \cline { 5 - 6 } & $n$ & & & $n$ & $\alpha$ \\
\hline Young & 29 & .99 & & 26 & .99 \\
Old & 32 & .97 & & 25 & .99 \\
\hline
\end{tabular}

$n=$ number of participants; $\alpha=$ Cronbach's alpha assessing the internal consistency of ratings by different participants

1986) on a scale from -100 to 100 . Specifically, they were instructed to assign high positive numeric values if the presented word elicited positive and pleasant feelings or emotions, and to assign large negative numeric values if the presented word elicited negative and unpleasant feelings or emotions; neutral words that elicited neither positive nor negative feelings or emotions should be assigned a value close to zero. Moreover, participants were also explicitly advised only to rate the presented word and not to include associated words that were evoked by the presented word in their rating. The specific wording of the instructions for imageability and emotionality ratings is provided in the Appendix.

\section{Results}

\section{Reliability of ratings}

The internal consistency of ratings by different participants for the 25 anchor items, as assessed with Cronbach's $\alpha$, was high for both age groups and for the imageability as well as for the emotionality ratings ( $\alpha \geq .97$; Table 1$)$. Similarly, across

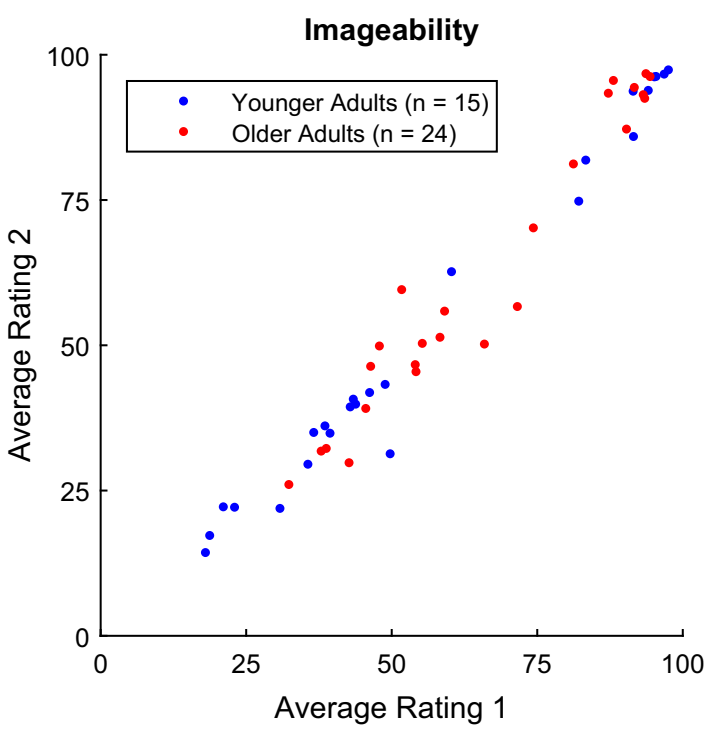

sessions, the rank-order stability of the average imageability and emotionality ratings for the 25 anchor words was high within both age groups ( $r \geq .97$; Fig. 3, Table 2). However, it should be noted that $\alpha$ and reliability was estimated only for the 25 anchor words presented at the very beginning of the rating session; as a consequence, the consistency and stability values presented here may not be representative of the full set of words.

\section{Validity of the ratings}

The correlations with the word norms previously reported in Hager and Hasselhorn (1994b) for imageability (Bildhaftigkeit) and emotionality (valence; Valenz) were very high ( $r \geq .87$; Fig. 4 , Table 3$)$, indicating the validity of our procedure and ratings as compared to the existing German word norms. Moreover, no age differences could be observed with respect to the rank-order stability of imageability and emotionality ratings as compared to the older word norms (i.e., equally high correlation coefficients across both age groups).

\section{Mean level differences of ratings and correlations of the ratings between age groups}

Absolute differences in the overall mean levels of ratings between the age groups were observed, whereas no clear effect of gender was found (Table 4). The mean level difference amounted to eight points on the 0 to 100 scale (Cohen's $d=$ 0.38 ) for imageability, and six points on the -100 to 100 scale $(d=0.20)$ for emotionality ratings, with a higher mean level for older adults on both rated categories. Exhaustion of the rating scale was higher for younger adults for the imageability

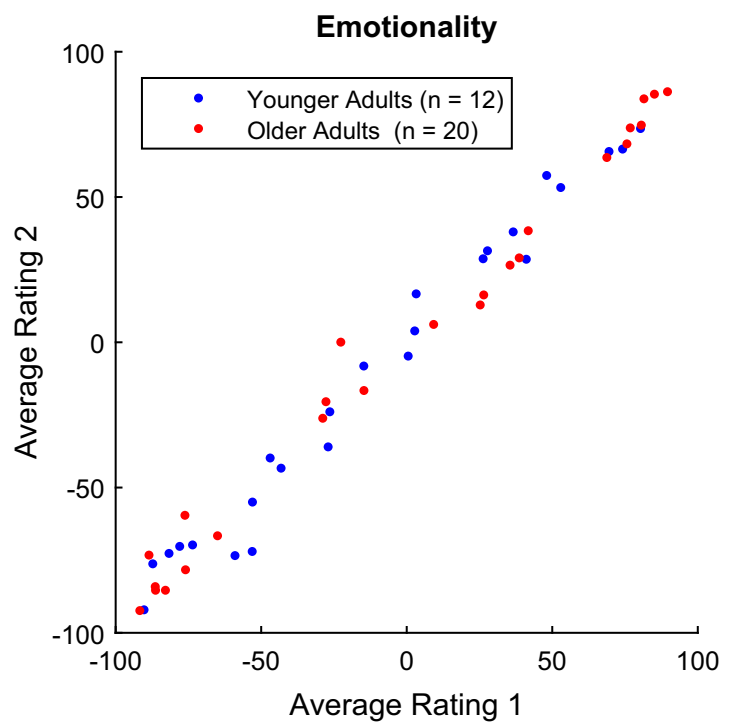

Fig. 3 Reliability of the average imageability and emotionality ratings. Dots represent the 25 anchor words, and Ratings 1 and 2 refer to the word ratings obtained from two sessions. 
Table 2 Retest stability of the aggregated imageability and emotionality ratings across two sessions ( 25 words)

\begin{tabular}{|c|c|c|c|c|c|c|}
\hline \multirow[t]{2}{*}{ Age Group } & \multicolumn{3}{|c|}{ Imageability } & \multicolumn{3}{|c|}{ Emotionality } \\
\hline & $n$ & $r$ & $\rho$ & $n$ & $r$ & $\rho$ \\
\hline Young & 15 & .99 & .97 & 12 & .99 & .99 \\
\hline Old & 24 & .97 & .94 & 20 & .99 & .99 \\
\hline
\end{tabular}

$n=$ number of participants contributing to the aggregated ratings; $r=$ Pearson correlation coefficient; $\rho=$ Spearman correlation coefficient

ratings, with older adults making on aggregate less use of the lowest $20 \%$ of the scale, explaining the age difference in imageability ratings. For emotionality ratings, older adults used the scale more extensively than did younger adults, with a shift toward more positive emotionality ratings (Fig. 5).

Correlations of the average ratings across gender and age groups were very high (Table 5). Within age groups, the correlations between males and females were at least $r=.87$. Across age groups, the correlations were found to be $r=.94$ for imageability and $r=.85$ for emotionality ratings (Fig. 6).

\section{Characteristic differences in word ratings between age groups}

A closer look at the words with the largest age differences in imageability and emotionality revealed characteristic differences between the age groups (Table 6), underscoring the usefulness of age-specific norms. Furthermore, younger adults indicated words more often as "unknown." Across the 2592 words presented, 29 words for younger and only three words for older adults were indicated in more than $5 \%$ of the ratings as "unknown." In all, 2471 words (95.3\%) received valid (i.e.,
Table 3 Validity of the ratings, as compared to the word norms reported in Hager and Hasselhorn (1994b)

\begin{tabular}{llllll}
\hline Age Group & Imageability (725 words) & & \multicolumn{2}{l}{$\begin{array}{l}\text { Emotionality } \\
(556 \text { words })\end{array}$} \\
\cline { 2 - 3 } \cline { 5 - 6 } \cline { 5 - 6 } & $r$ & $\rho$ & & $r$ & $\rho$ \\
\hline Younger & .87 & .86 & & .92 & .90 \\
Older & .87 & .86 & & .89 & .86 \\
Younger and older & .88 & .87 & & .93 & .91 \\
\hline
\end{tabular}

$r=$ Pearson correlation coefficient; $\rho=$ Spearman correlation coefficient

no "unknown") ratings by all participants. Table 7 provides an overview of the most frequent words indicated as "unknown."

\section{Discussion}

The goal of the present study was to collect age-comparative imageability and emotionality ratings for a large body of German nouns from younger (21-31 years) and older (7086 years) adults, and to make this information available to other researchers. Ratings were initially collected to control for imageability and emotionality of words across two age groups in memory tasks in a large-scale cognitive training study (Schmiedek et al., 2010) as these word characteristics have been repeatedly reported to influence recognition and recall probability of words (e.g., Adelman \& Estes, 2013; Cortese, McCarty, \& Schock, 2010; Cortese et al., 2015; Kensinger et al., 2002; Paivio et al., 1969; Rubin \& Friendly, 1986). Nonetheless, the information may prove useful also in other experimental contexts (e.g., Balota et al., 2004; Cortese \& Fugett, 2004).

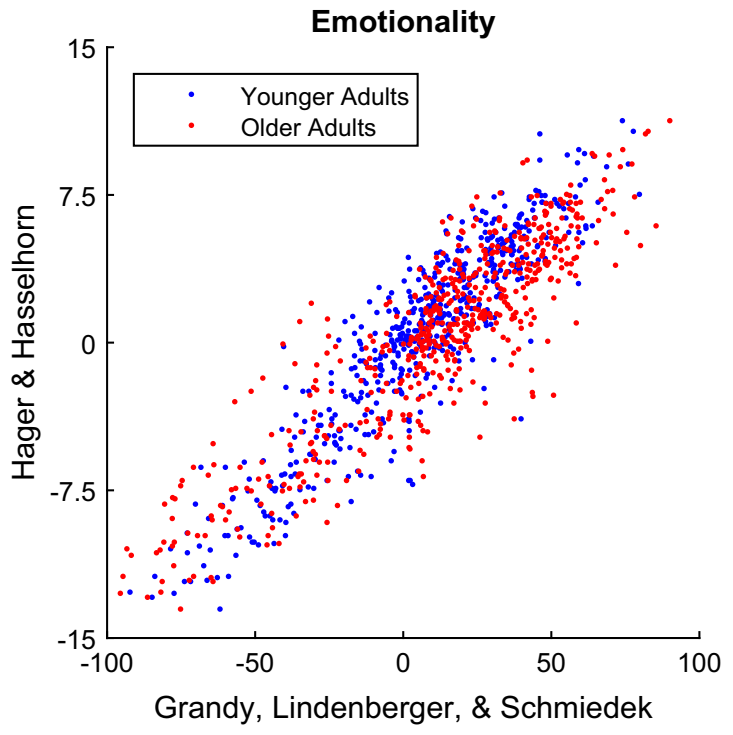

Fig. 4 Validity of the ratings in our study as compared to the word norms reported in Hager and Hasselhorn (1994b). 
Table 4 Age and gender differences in the mean levels of ratings

\begin{tabular}{|c|c|c|c|c|c|}
\hline \multirow[t]{2}{*}{ Age Group } & \multirow[t]{2}{*}{ Gender } & \multicolumn{2}{|l|}{ Imageability } & \multicolumn{2}{|l|}{ Emotionality } \\
\hline & & Mean $\pm S D$ [Range $]$ & $d$ & Mean $\pm S D$ [Range $]$ & $d$ \\
\hline Young & $\begin{array}{l}\text { Male } \\
\text { Female }\end{array}$ & $\begin{array}{l}66.3 \pm 21.9[6.797 .1] \\
66.7 \pm 25.9[4.298 .6]\end{array}$ & 0.02 & $\begin{array}{l}9.3 \pm 26.0[-87.280 .1] \\
9.8 \pm 28.4[-97.485 .9]\end{array}$ & 0.02 \\
\hline Old & $\begin{array}{l}\text { Male } \\
\text { Female }\end{array}$ & $\begin{array}{l}74.8 \pm 21.4\left[\begin{array}{ll}13.3 & 98.9\end{array}\right] \\
74.3 \pm 17.8[20.396 .9]\end{array}$ & -0.03 & $\begin{array}{l}15.4 \pm 32.1[-100.092 .8] \\
15.3 \pm 32.1[-96.990 .4]\end{array}$ & 0.00 \\
\hline $\begin{array}{l}\text { Young } \\
\text { Old }\end{array}$ & & $\begin{array}{l}66.5 \pm 23.5[7.497 .7] \\
74.6 \pm 19.3[22.497 .1]\end{array}$ & 0.38 & $\begin{array}{r}9.5 \pm 26.3[-92.379 .9] \\
15.4 \pm 31.4[-98.490 .0]\end{array}$ & 0.20 \\
\hline
\end{tabular}

$d=$ Cohen's $d$

Internal consistency (Cronbach's $\alpha$ ) and retest rank-order stability of ratings were very high for both age groups. Also, the validity of our ratings as compared to ratings collected and published by Hager and Hasselhorn (1994b) was found to be very high $(r \geq .86)$. Thus, our ratings provide a reliable and valid representation of the constructs imageability and emotionality (valence) as compared to previous instantiations, which ensures that findings obtained with our ratings may be integrated into the existing literature on a sound basis.

The ratings showed substantial rank-order stability across younger and older adults (imageability, $r=.94$; emotionality, $r=.85$ ). That is, younger and older adults displayed on a general level a large degree of agreement regarding imageability and emotionality of nouns. Nevertheless, younger and older adults differed in the overall mean levels of ratings (imageability, $d=0.38$; emotionality, $d=0.20$ ) as well as the extent to which they used the rating scales (imageability, $S D=$ 24 vs. 19 ; emotionality, $S D=26$ vs. 31 ), indicating a slightly

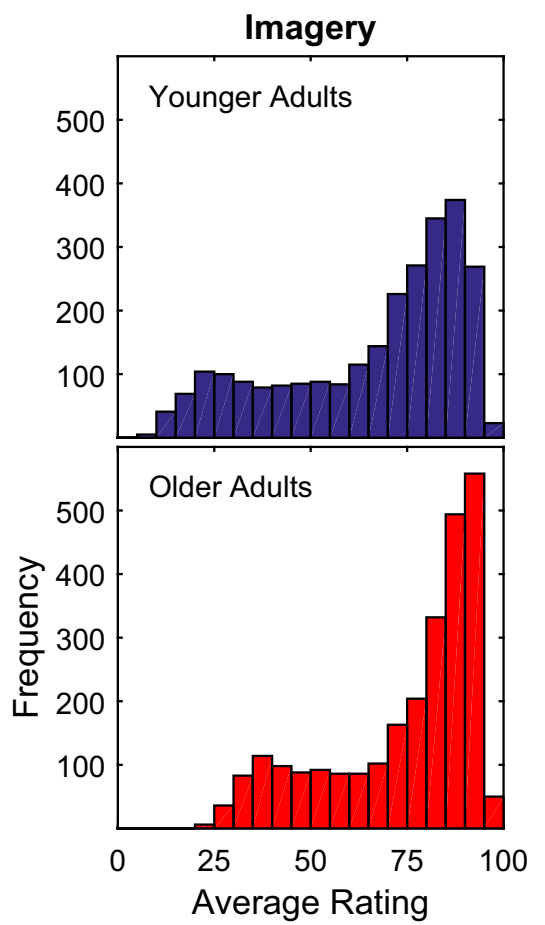

higher mean anchor for the scales in the older adults, with a less extant use of the rating scale for imageability and a more extant use of the rating scale for emotionality. Figure 6 reveals that for imageability older adults rated words consistently higher than younger adults, whereas for emotionality, older adults rated words of positive emotionality more positive and of negative emotionality more negative than younger adults (in line with Grühn \& Smith, 2008). Accordingly, for imageability the mean level difference was more pronounced between age groups, whereas the usage of the rating scale was reduced in the older adults due to a "bias" toward higher imageability. A likely explanation for this finding is that older adults due to their larger cumulative experience across their lifespan more easily invoke a mental image for a word than younger adults.

In a similar vein, characteristic differences in imageability and emotionality ratings were observed between younger and older adults (Table 6). For instance, for older adults the better

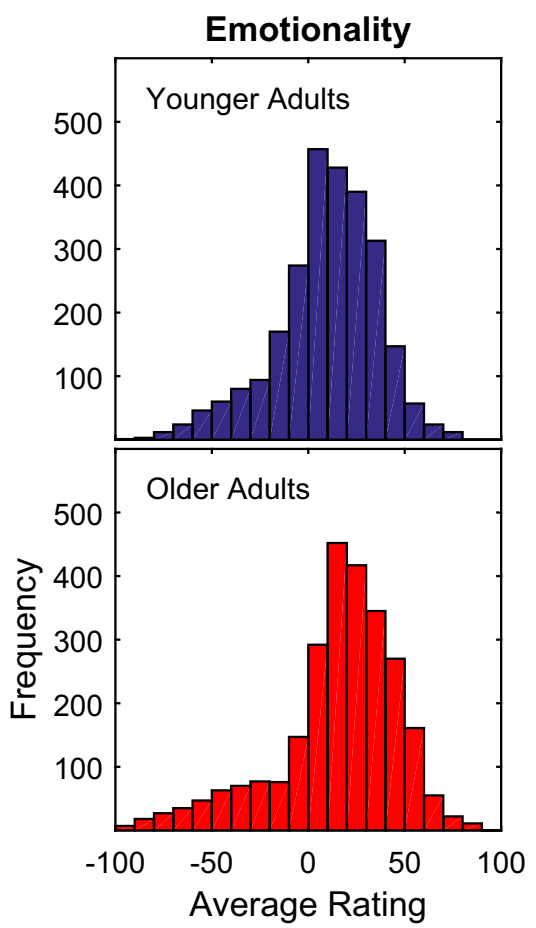

Fig. 5 Age comparison of the distributions of ratings for imageability and emotionality. 
Table 5 Correlations of average ratings across subgroups

\begin{tabular}{llllll}
\hline Groups & \multicolumn{2}{l}{ Imageability } & & \multicolumn{2}{l}{ Emotionality } \\
\cline { 2 - 3 } & $r$ & $\rho$ & & $r$ & $\rho$ \\
\hline Young (Female vs. Male) & .94 & .91 & & .87 & .84 \\
Old (Female vs. Male) & .91 & .85 & & .91 & .86 \\
Young vs. Old (Female and Male) & .94 & .89 & & .85 & .81 \\
\hline
\end{tabular}

$r=$ Pearson correlation coefficient; $\rho=$ Spearman correlation coefficient

imageability of the word "son" quite plausibly results from concrete life experiences they can resort to which younger adults have not (yet) made. On the other hand, younger adults may have had more exposition, for instance, to visual media (movies) that contain mythical or fantasy creatures like "fairies," "ghosts," "witches," and so forth, and as a consequence more easily invoke mental images for these words than older adults do. Similarly, the distinctly more positive emotionality ratings of "discipline", "work", "duty", "pope", "god", or "chapel” of older adults may be strongly reflecting generational and societal changes. Notably, as Table 6 shows the words with the largest rating differences between age groups, it appears that differences between age groups may be rooted in different evaluations of whole semantic categories, as, for instance, the abovementioned words may be subsumed under semantic categories like "myths/fantasy," "religion," or "virtues." Furthermore, in line with the notion of higher crystallized intelligence ("pragmatics") as a consequence of lifelong acquisition of knowledge (Baltes, 1987; Baltes, Staudinger, \& Lindenberger, 1999), older adults indicated far fewer words as "unknown" than younger adults. In sum, and importantly so, our findings indicate that there are systematic differences between younger and older adults and strongly support our conjecture that the existence of age-specific imageability and emotionality norms is highly desirable for research on cognitive aging and the cognitive neuroscience of aging.

To exemplify this point, in a comprehensive study by Balota et al. (2004) imageability has been shown to explain a substantial amount of variance in reaction times in a lexical decision task for both younger and older adults over and above several phonological features and lexical variables. In addition, an age dependent effect was observed in the amount of additional variance explained; on the basis of the Cortese and Fugett (2004) imageability ratings (obtained from undergraduate students), imageability accounted for an additional $7.2 \%$ of variance in reaction times in younger adults, as compared to $5.3 \%$ in older adults. Although this may be attributable to age-related differences in cognitive processes engaged (e.g., older adults relying less on semantic information in this specific task), an alternative explanation is that the lower additional variance explained in older adults is due to a limited generalizability of the imageability norms obtained from younger adults to older adults. That is, because we observed systematic differences in the imageability of words between younger and older adults, variance in the imageability of words in older adults was not accounted for by the imageability ratings of younger adults, thus reducing their predictive power for older adults. Of note, this is not to say that younger adults' ratings are to be considered generally invalid for predicting the cognitive performance of older adults. In line with the high rank-order stability between the ratings of younger and older adults observed in our study, the general correlational pattern in the Balota et al. (2004) study was found to be consistent across age groups. Nevertheless, this example well illustrates that when dissecting more subtle differences between age groups, as in this case the
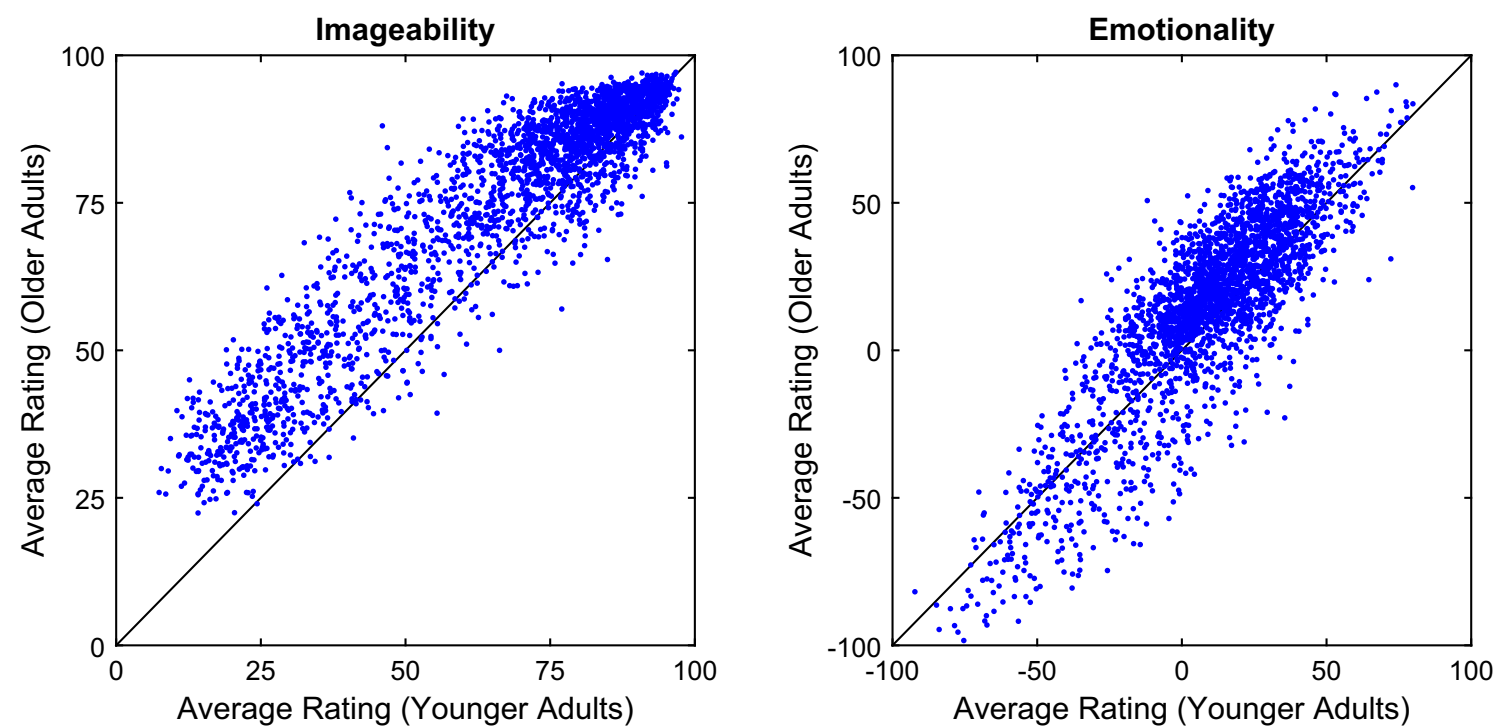

Fig. 6 Correlations of average ratings across age groups. The black lines indicate where identical ratings between younger and older adults would lie and help visualize differences in the ratings between younger and older adults. 
Table 6 Largest differences in average ratings between older (OA) and younger (YA) adults

\begin{tabular}{|c|c|c|c|c|c|c|c|}
\hline \multicolumn{4}{|l|}{ Ratings $\mathrm{YA}>\mathrm{OA}$} & \multicolumn{4}{|l|}{ Ratings $\mathrm{YA}<\mathrm{OA}$} \\
\hline Word & $\Delta$ & YA & $\mathrm{OA}$ & Word & $\Delta$ & YA & $\mathrm{OA}$ \\
\hline Fee (fairy) & 20 & 77 & 57 & Sohn (son) & -42 & 46 & 88 \\
\hline Gespenst (ghost) & 20 & 85 & 65 & Garbe (sheaf) & -37 & 47 & 84 \\
\hline Pluto (Pluto) & 16 & 66 & 50 & Rückgrat (backbone) & -36 & 40 & 77 \\
\hline Schimmer (glimmer) & 16 & 55 & 39 & Schlemmer (glutton) & -36 & 33 & 68 \\
\hline Mammut (mammoth) & 15 & 91 & 76 & Sonntag (Sunday) & -35 & 41 & 76 \\
\hline Schleim (slime) & 14 & 79 & 65 & Gramm (gram) & -35 & 26 & 61 \\
\hline Hexe (witch) & 14 & 87 & 73 & Rundfunk (broadcast) & -34 & 38 & 72 \\
\hline Teufel (devil) & 14 & 80 & 66 & Gehalt (salary) & -34 & 29 & 63 \\
\hline Pinzette (tweezers) & 14 & 95 & 81 & Waise (orphan) & -34 & 35 & 69 \\
\hline Stinktier (skunk) & 14 & 87 & 73 & Rätsel (puzzle) & -33 & 42 & 75 \\
\hline \multicolumn{8}{|l|}{ Emotionality } \\
\hline Ratings YA > OA & & & & Ratings $\mathrm{YA}<\mathrm{OA}$ & & & \\
\hline Word & $\Delta$ & YA & $\mathrm{OA}$ & Word & $\Delta$ & YA & $\mathrm{OA}$ \\
\hline Panther (panther) & 58 & 36 & -23 & Disziplin (discipline) & -63 & 12 & 51 \\
\hline Gewitter (tempest) & 53 & 22 & -31 & Arbeit (work) & -53 & -9 & 44 \\
\hline Vampir (vampire) & 53 & -4 & -57 & Pflicht (duty) & -52 & -26 & 26 \\
\hline Unterwelt (underworld) & 51 & -14 & -66 & Papst (pope) & -52 & -35 & 17 \\
\hline Dschungel (jungle) & 51 & 30 & -21 & Gott (god) & -50 & 2 & 52 \\
\hline Bumerang (boomerang) & 49 & 37 & -12 & Glucke (clucking hen) & -50 & -22 & 28 \\
\hline Drache (dragon) & 49 & 17 & -32 & Elite (elite) & -49 & -18 & 31 \\
\hline Revolver (revolver) & 49 & -26 & -75 & Wohnblock (housing block) & -48 & -24 & 24 \\
\hline Floh (flea) & 49 & -17 & -66 & Pfleger (nurse) & -48 & -7 & 41 \\
\hline Gespenst (ghost) & 48 & -3 & -51 & Kapelle (chapel) & -45 & 9 & 54 \\
\hline
\end{tabular}

$\Delta=$ age difference in ratings

differential utilization of semantic variables in lexical decision, it may prove difficult to fully distinguish between true age-

Table 7 Most frequent "unknown" words by younger and older adults

\begin{tabular}{llllr}
\hline Younger Adults & & & Older Adults \\
\cline { 5 - 5 } Word & $\%$ & & Word & $\%$ \\
\hline Garbe (sheaf) & 32 & & Tunika (tunic) & 11 \\
Egge (harrow) & 25 & & Kaftan (caftan) & 7 \\
Zobel (sable) & 24 & & Amphore (amphora) & 7 \\
Litanei (litany) & 22 & & \\
Kaftan (caftan) & 21 & & \\
Quaste (tassel) & 21 & & \\
Schalmei (shawm) & 21 & & \\
Blesse (blaze) & 19 & & \\
Neglige (negligee) & 18 & \\
Humpen (beaker) & 17 &
\end{tabular}

$\%=$ relative frequency of participants indicating the word as "unknown" (across imageability and emotionality ratings) related differences in actual cognitive processing and agerelated differences induced by word ratings that are biased to some degree, when these were obtained from only one age group.

To conclude, the age-specific imageability and emotionality ratings for 2592 German nouns collected in this study provide useful information to control or manipulate stimulus material in experiments that involve younger and older adults. Previous findings highlighted the significance of imageability and emotionality of words, for instance, for their memorability. The existence of considerable and characteristic differences between the two age groups underscores the importance of carefully matching word material across age groups. The word ratings can be found in the electronic supplementary material 2 .

Author note We thank Colin Bauer for programming the task, as well as all research assistants involved in data collection. We thank Michael Cortese for a kind and helpful review.

Funding Information Open access funding provided by Projekt DEAL. 
Open Access This article is licensed under a Creative Commons Attribution 4.0 International License, which permits use, sharing, adaptation, distribution and reproduction in any medium or format, as long as you give appropriate credit to the original author(s) and the source, provide a link to the Creative Commons licence, and indicate if changes were made. The images or other third party material in this article are included in the article's Creative Commons licence, unless indicated otherwise in a credit line to the material. If material is not included in the article's Creative Commons licence and your intended use is not permitted by statutory regulation or exceeds the permitted use, you will need to obtain permission directly from the copyright holder. To view a copy of this licence, visit http://creativecommons.org/licenses/by/4.0/.

\section{References}

Adelman, J. S., \& Estes, Z. (2013). Emotion and memory: A recognition advantage for positive and negative words independent of arousal. Cognition, 129, 530-535. https://doi.org/10.1016/j.cognition.2013. 08.014

Baayen, R. H., Piepenbrock, R., \& Gulikers, L. (1995). The CELEX lexical database (CD-ROM). University of Pennsylvania, Philadelphia, PA: Linguistic Data Consortium.

Balota, D. A., Cortese, M. J., Sergent-Marshall, S. D., Spieler, D. H., \& Yap, M. (2004). Visual word recognition of single-syllable words. Journal of Experimental Psychology: General, 133, 283-316. https://doi.org/10.1037/0096-3445.133.2.283

Baltes, P. B. (1987). Theoretical propositions of life-span developmental psychology: On the dynamics between growth and decline. Developmental Psychology, 23, 611-626. https://doi.org/10.1037/ 0012-1649.23.5.611

Baltes, P. B., Staudinger, U. M., \& Lindenberger, U. (1999). Lifespan psychology: Theory and application to intellectual functioning. Annual Review of Psychology, 50, 471-507. https://doi.org/10. 1146/annurev.psych.50.1.471

Baschek, I.-L., Bredenkamp, J., Oehrle, B., \& Wippich, W. (1977). Bestimmung der Bildhaftigkeit (I), Konkretheit (C), und der Bedeutungshaltigkeit (m') von 800 Substantiven. Zeitschrift fur Experimentelle und Angewandte Psychologie, 24, 353-396.

Bower, G. H. (1970). Imagery as a relational organizer in associative learning. Journal of Verbal Learning and Verbal Behavior, 9, 529533. https://doi.org/10.1016/S0022-5371(70)80096-2

Brod, G., Werkle-Bergner, M., \& Shing, Y. L. (2013). The influence of prior knowledge on memory: A developmental cognitive neuroscience perspective. Frontiers in Behavioral Neuroscience, 7, 139. https://doi.org/10.3389/fnbeh.2013.00139

Charles, S. T., Mather, M., \& Carstensen, L. L. (2003). Aging and emotional memory: The forgettable nature of negative images for older adults. Journal of Experimental Psychology: General, 132, 310324. https://doi.org/10.1037/0096-3445.132.2.310

Cortese, M. J., \& Fugett, A. (2004). Imageability ratings for 3,000 monosyllabic words. Behavior Research Methods, Instruments, \& Computers, 36, 384-387. https://doi.org/10.3758/BF03195585

Cortese, M. J., Khanna, M. M., \& Hacker, S. (2010). Recognition memory for 2,578 monosyllabic words. Memory, 18, 595-609. https:// doi.org/10.1080/09658211.2010.493892

Cortese, M. J., McCarty, D. P., \& Schock, J. (2015). A mega recognition memory study of 2897 disyllabic words. Quarterly Journal of Experimental Psychology, 68, 1489-1501. https://doi.org/10.1080/ 17470218.2014 .945096

Cronbach, L. J. (1951). Coefficient alpha and the internal structure of tests. Psychometrika, 16, 297-334. https://doi.org/10.1007/ BF02310555
Emmerich, H. J. (1979). Developmental differences in ratings of meaningfulness, concreteness, and picturability. Developmental Psychology, 15, 464-466. https://doi.org/10.1037/0012-1649.15.4. 464

Forisha, B. D. (1975). Mental imagery verbal processes: A developmental study. Developmental Psychology, 11, 259-267. https://doi.org/10. 1037/h0076569

Grühn, D., Scheibe, S., \& Baltes, P. B. (2007). Reduced negativity effect in older adults' memory for emotional pictures: The heterogeneityhomogeneity list paradigm. Psychology and Aging, 22, 644-649. https://doi.org/10.1037/0882-7974.22.3.644

Grühn, D., \& Smith, J. (2008). Characteristics for 200 words rated by young and older adults: Age-dependent evaluations of German adjectives (AGE). Behavior Research Methods, 40, 1088-1097. https://doi.org/10.3758/BRM.40.4.1088

Grühn, D., Smith, J., \& Baltes, P. B. (2005). No aging bias favoring memory for positive material: Evidence from a heterogeneityhomogeneity list paradigm using emotionally toned words. Psychology and Aging, 20, 579-588. https://doi.org/10.1037/08827974.20.4.579

Hager, W., \& Hasselhorn, M. (1994a). Instruktionen, Skalen und Versuchspersonenökonomie bei der Einschätzung von kognitivsematischen Wortattributen. In W. Hager \& M. Hasselhorn (Eds.), Handbuch deutschsprachiger Wortnormen. Göttingen, Germany: Hogrefe.

Hager, W., \& Hasselhorn, M. (Eds.). (1994b). Handbuch deutschsprachiger Wortnormen. Göttingen, Germany: Hogrefe.

Hamann, S. B. (2001). Cognitive and neural mechanisms of emotional memory. Trends in Cognitive Sciences, 5, 394 400. https://doi.org/ 10.1016/S1364-6613(00)01707-1

Hamann, S. B., Cahill, L., \& Squire, L. R. (1997). Emotional perception and memory in amnesia. Neuropsychology, 11, 104-113. https://doi. org/10.1037/0894-4105.11.1.104

Kanske, P., \& Kotz, S. A. (2010). Leipzig Affective Norms for German: A reliability study. Behavior Research Methods, 42, 987-991. https://doi.org/10.3758/BRM.42.4.987

Kensinger, E. A., Brierley, B., Medford, N., Growdon, J. H., \& Corkin, S. (2002). Effects of normal aging and Alzheimer's disease on emotional memory. Emotion, 2, 118-134. https://doi.org/10.1037/15283542.2.2.118

Lahl, O., Göritz, A. S., Pietrowsky, R., \& Rosenberg, J. (2009). Using the World-Wide web to obtain large-scale word norms: 190,212 ratings on a set of 2,654 German nouns. Behavior Research Methods, 41, 13-19. https://doi.org/10.3758/BRM.41.1.13

Lindenberger, U. (2014). Human cognitive aging: Corriger la fortune? Science, 346, 572-578. https://doi.org/10.1126/science.1254403

Offe, H., Anneken, G., \& Kessler, E. (1981). Normen für die Konkretheits- und Vorstellbarkeitseinschätzungen von 234 Substantiven. Psychologische Beitrage, 23, 65-85.

Paivio, A. (1965). Abstractness, imagery, and meaningfulness in pairedassociate learning. Journal of Verbal Learning and Verbal Behavior, 4, 32-38. https://doi.org/10.1016/S0022-5371(65)80064-0

Paivio, A. (1971). Imagery and verbal processes. New York, NY: Holt, Rinehart \& Winston.

Paivio, A., Yuille, J. C., \& Madigan, S. A. (1968). Concreteness, imagery, and meaningfulness values for 925 nouns. Journal of Experimental Psychology, 76(1, Pt. 2), 1-25. https://doi.org/10.1037/h0025327

Paivio, A., Yuille, J. C., \& Rogers, T. B. (1969). Noun imagery and meaningfulness in free and serial recall. Journal of Experimental Psychology, 79, 509-514. https://doi.org/10.1037/h0026930

Richardson, J. E. (1998). The availability and effectiveness of reported mediators in associative learning: A historical review and an experimental investigation. Psychonomic Bulletin \& Review, 5, 597-614. https://doi.org/10.3758/BF03208837

Rubin, D. C., \& Friendly, M. (1986). Predicting which words get recalled: Measures of free recall, availability, goodness, emotionality, and 
pronunciability for 925 nouns. Memory \& Cognition, 14, 79-94. https://doi.org/10.3758/BF03209231

Schmidtke, D. S., Schröder, T., Jacobs, A. M., \& Conrad, M. (2014). ANGST: Affective norms for German sentiment terms, derived from the affective norms for English words. Behavior Research Methods, 46, 1108-1118. https://doi.org/10.3758/ s13428-013-0426-y

Schmiedek, F., Lövdén, M., \& Lindenberger, U. (2010). Hundred days of cognitive training enhance broad cognitive abilities in adulthood: Findings from the COGITO study. Frontiers in Aging Neuroscience, 2, 27. https://doi.org/10.3389/fnagi. 2010.00027

Schwibbe, M., Räder, K., Schwitte, G., Borchardt, M., \& GeikenPophanken, G. (1981). Zum emotionalen Gehalt von Substantiven, Adjektiven und Verben. Zeitschrift fur Experimentelle und Angewandte Psychologie, 28, 486-501.

Shing, Y. L., Werkle-Bergner, M., Brehmer, Y., Müller, V., Li, S.-C., \& Lindenberger, U. (2010). Episodic memory across the lifespan: The contributions of associative and strategic components. Neuroscience \& Biobehavioral Reviews, 34, 1080-1091. https://doi.org/10.1016/j. neubiorev.2009.11.002
Shing, Y. L., Werkle-Bergner, M., Li, S.-C., \& Lindenberger, U. (2008). Associative and strategic components of episodic memory: A life-span dissociation. Journal of Experimental Psychology: General, 137, 495-513. https://doi.org/10.1037/ 0096-3445.137.3.495

Singer, T., Lindenberger, U., \& Baltes, P. B. (2003). Plasticity of memory for new learning in very old age: A story of major loss? Psychology and Aging, 18, 306-317. https://doi.org/10.1037/0882-7974.18.2. 306

Toglia, M. P., \& Battig, W. F. (1978). Handbook of semantic word norms. Hilldsale, NJ: Erlbaum.

Võ, M. L. H., Conrad, M., Kuchinke, L., Urton, K., Hofmann, M. J., \& Jacobs, A. M. (2009). The Berlin Affective Word List Reloaded (BAWL-R). Behavior Research Methods, 41, 534-538. https://doi. org/10.3758/BRM.41.2.534

Võ, M. L. H., Jacobs, A. M., \& Conrad, M. (2006). Cross-validating the Berlin Affective Word List. Behavior Research Methods, 38, 606609. https://doi.org/10.3758/BF03193892

Publisher's note Springer Nature remains neutral with regard to jurisdictional claims in published maps and institutional affiliations. 